\title{
Legal medicine: assessing mental capacity and writing medical reports for deputy applications
}

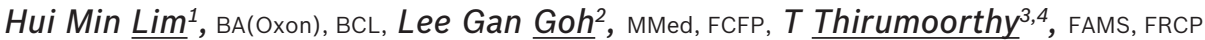

\begin{abstract}
Medical reports are required to support court applications to appoint a deputy to make decisions on behalf of a person who has lost mental capacity. The doctor writing such a medical report needs to be able to systematically assess the mental capacity of the person in question, in order to gather the necessary evidence for the court to make a decision. If the medical report is not adequate, the application will be rejected and the appointment of the deputy delayed. This article sets out best practices for performing the assessment and writing the medical report, common errors, and issues of concern.
\end{abstract}

Keywords: appointment of deputy, medical report, mental capacity, Mental Capacity Act, mental state assessment

\section{INTRODUCTION Objectives}

This paper updates the reader on the need to certify the mental capacity of a person for various matters, in particular, to support a court application appointing a deputy for him/her; the legal requirements for a medical report supporting such an application; and how to assess mental capacity.

\section{Appointment of donee(s)}

The Mental Capacity Act (MCA), Singapore, allows persons with mental capacity to voluntarily make a Lasting Power of Attorney (LPA) appointing one or more persons, as donee(s), to make decisions on their behalf if and when they lose mental capacity. A donee may be appointed for matters relating to the person's personal welfare, and/or his property and affairs..$^{(1)}$ With the exception of psychiatrists, all medical practitioners need to be accredited by the Public Guardian to be a 'certificate issuer' to certify that the person has the capacity to make the LPA. This can be done by attending a prescribed course, which is available online at the Singapore Medical Association's website. ${ }^{(2)}$

\section{Appointment of a deputy \\ In cases where an LPA was not made before the loss of mental capacity, the MCA allows a deputy to be appointed by the court to make decisions on behalf of the person (P). ${ }^{(3)} A$ deputy can be appointed for matters regarding personal welfare, and/or property and affairs. ${ }^{(3)}$ The individual applying to become P's deputy is usually a relative or close friend.}

\section{Medical report required for deputy application}

The court application to appoint a deputy (deputy application) must state whether the applicant wishes to be $\mathrm{P}^{\prime} \mathrm{s}$ deputy in terms of personal welfare, and/or property and affairs. It must be accompanied by a doctor's affidavit exhibiting a medical report, which must state whether $\mathrm{P}$ lacks capacity either in relation to his personal welfare, or his property and affairs, or both (depending on what the court application requires). The court will rely on the medical report to decide whether $\mathrm{P}$ lacks mental capacity in any of the areas mentioned, which is a decision that must be made before a deputy can be appointed for $\mathrm{P}$ in that area. If the medical report is inadequate, the court will reject the deputy's application. ${ }^{(4)}$

\section{MEDICAL REPORT WRITING}

\section{Standard template - Form 224}

All medical reports for deputy applications must be in the standard template set out in Form 224 in the Family Justice Courts Practice Directions 2015. ${ }^{(5)}$ There are five sections to the form (Table I). Doctors should not use their own template or add a report written in their own format to the template. Every box in the template, which is available online or requested from the lawyer acting for the applicant, should be filled out. ${ }^{(6)}$

\section{Areas to pay attention to \\ Lapse of time between date of last examination of $P$ and date of report}

The acceptable lapse of time between the date of the last examination of $\mathrm{P}$ and the date of the report depends on (a) how established the relationship between the doctor and $\mathrm{P}$ is; and (b) whether $\mathrm{P}^{\prime} \mathrm{s}$ condition is permanent or temporary (i.e. is there a possibility that $\mathrm{P}$ could recover from this state). Hence, it is necessary to state: (a) details of the doctor-patient relationship, i.e. how long the doctor has known P (e.g. the patient first came to see me in 2010); how regularly $P$ has been seeing the doctor (e.g. the patient has come to me for regular follow-up 2-3 times a year in the past five years); the date of the doctor's last examination of $\mathrm{P}$; (b) whether $\mathrm{P}$ 's condition is permanent or temporary, and the reasons for this conclusion.

\footnotetext{
${ }^{1}$ The Legal Aid Bureau, ${ }^{2}$ Division of Family Medicine, Department of Medicine, National University Health System, ${ }^{3}$ Duke-NUS Medical School, ${ }^{4}$ Centre for Medical Ethics and Professionalism, Singapore Medical Association, Singapore

Correspondence: Ms Hui Min Lim, The Legal Aid Bureau, 45 Maxwell Road \#07-11, The URA Centre (East Wing), Singapore 069118. lim_hui_min@lab.gov.sg
} 
Table I. Form 224 and the information required.

\begin{tabular}{|c|c|c|}
\hline Section & Heading & Information required \\
\hline 1 & Patient's particulars & $\begin{array}{l}\text { - Full name } \\
\text { - NRIC/FIN/passport number } \\
\text { - Age }\end{array}$ \\
\hline 2 & Doctor's particulars & $\begin{array}{l}\text { - Full name } \\
\text { - NRIC/FIN/passport number } \\
\text { - Medical Council registration number } \\
\text { - Hospital/clinic name and address } \\
\text { - Doctor's qualifications and experience } \\
\text { - Doctor-patient relationship: to state whether the doctor has been seeing P regularly, or only for the } \\
\text { purpose of the mental capacity assessment; if the former, to state when the doctor first started } \\
\text { seeing P, when he last saw } P \text {, and the frequency with which he saw } P \text { in between these dates (see } \\
\text { 'Lapse of time between date of last examination of } P \text { and date of report') }\end{array}$ \\
\hline 3 & $\begin{array}{l}\text { Patient's medical } \\
\text { information }\end{array}$ & $\begin{array}{l}\text { - P's clinical history: to state the source of the information on P's clinical history (i.e. whether the } \\
\text { information came from medical records, P himself, P's caregiver, etc) } \\
\text { - Findings from physical examination/mental state examination: to state the doctor's observations of P } \\
\text { (i.e. P's demeanour, body language, tone of voice, etc), if relevant to the doctor's assessment of P's } \\
\text { mental capacity, as well as the doctor's interactions with P, the questions posed to P and answers } \\
\text { given by P, and the date of examination } \\
\text { - Relevant investigation results: to state the results of computed tomography and magnetic resonance } \\
\text { imaging of the brain, and other investigations performed, if any } \\
\text { - Diagnosis: to state the impairment or disturbance to the functioning of P's mind or brain } \\
\text { (e.g. dementia, stroke, etc) }\end{array}$ \\
\hline 4 & $\begin{array}{l}\text { Opinion on patient's } \\
\text { mental capacity }\end{array}$ & $\begin{array}{l}\text { - The first part is a series of questions with 'Yes' and 'No' check boxes. Each question must be } \\
\text { answered by checking the 'Yes' or 'No' box. No question should be left out. The questions require the } \\
\text { doctor to state his opinion on the following issues - } \\
\text { (1) In relation to personal welfare issues, if P can: } \\
\text { (a) understand information relevant to a decision relating to his personal welfare } \\
\text { (b) retain information long enough to make such a decision } \\
\text { (c) weigh information as part of the process of making such a decision } \\
\text { (d) communicate his decision on the matter } \\
\text { (2) Taking 1a-d into consideration, whether P has mental capacity in respect of personal welfare } \\
\text { (3) In relation to property and affairs issues, whether P can: } \\
\text { (a) understand information relevant to a decision relating to his personal welfare } \\
\text { (b) retain information long enough to make such a decision } \\
\text { (c) weigh information as part of the process of making such a decision } \\
\text { (d) communicate his decision in the matter } \\
\text { (4) Taking 3a-d into consideration, whether P has mental capacity in respect of property and affairs } \\
\text { (a) Statement on basis of opinion given in respect of P's mental capacity: to state why the doctor } \\
\text { has checked the 'Yes' or 'No' boxes in the way that he has } \\
\text { (b) Prognosis: to state whether P is likely to regain mental capacity by checking either the 'Yes', } \\
\text { 'No' or 'Not Sure' box; if the doctor checks either the 'Yes' or 'Not sure' box, he must state the } \\
\text { date another assessment of P's mental capacity should be carried out } \\
\text { (c) Would the patient understand if he/she were informed of this application?; to check either the } \\
\text { 'Yes' or 'No' boxes } \\
\text { (d) Is the doctor aware of any other doctor who holds a different professional opinion regarding } \\
\text { the patient's mental capacity?: to state either 'Yes' (the doctor is aware of another doctor who } \\
\text { takes a different view from him on P's mental capacity) or 'No' (the doctor is not personally } \\
\text { aware, to the best of his knowledge and information, of any other doctor who takes a different } \\
\text { view from him on P's mental capacity); this item should not be left blank }\end{array}$ \\
\hline 5 & Declaration & $\begin{array}{l}\text { - The declaration requires the doctor to sign off on the following statement: } \\
\text { 'I have read and understood the provisions in Sections 3, 4, } 5 \text { of the Mental Capacity Act. } \\
\text { I believe in the correctness of the opinion set out herein. } \\
\text { I understand that in giving this report my duty is to the court and I confirm that I have complied with } \\
\text { this duty.' } \\
\text { - The purpose of this section is to ensure that the doctor: } \\
\text { (a) understands the framework for deciding whether a person has mental capacity and what a lack } \\
\text { of mental capacity means } \\
\text { (b) believes in the correctness of what he has written in the medical report } \\
\text { (c) is aware that his first duty is to the court, to give his impartial and honest opinion on P's } \\
\text { mental capacity, as a medical professional (and not to allow his opinion to be influenced or } \\
\text { swayed by P, his caregiver or other persons) } \\
\text { Sections } 3,4 \text { and } 5 \text { of the Mental Capacity Act are set out in the last two pages of Form } 224\end{array}$ \\
\hline
\end{tabular}

FIN: foreign identification number; NRIC: national registration identity card; P: the person whose mental capacity is being assessed 
In cases where: (a) the doctor has only seen $\mathrm{P}$ once or twice (e.g. the doctor only saw $\mathrm{P}$ as an outpatient on one occasion and $\mathrm{P}$ then defaulted on follow-up), the acceptable lapse is about $2-3$ months (subject to $\mathrm{P}^{\prime}$ s condition); (b) P is seen regularly over a few years, a lapse of 5-7 months may still be acceptable (subject to $\mathrm{P}^{\prime} \mathrm{s}$ condition); (c) $\mathrm{P}^{\prime} \mathrm{s}$ condition is permanent (e.g. vascular dementia with profound dementia), even 7-8 months or a year's lapse may be acceptable; and (d) $\mathrm{P}^{\prime} \mathrm{s}$ condition is not permanent (e.g. a head injury from a fall, but slowly recovering), then a lapse of not more than 3-6 months may be acceptable or, if $\mathrm{P}$ is in a vegetative state, the doctor should state whether this is a permanent condition (i.e. a persistent vegetative state).

\section{Tests to establish P's mental capacity}

The doctor should give careful consideration as to the most appropriate test of mental capacity to administer to ascertain $\mathrm{P}^{\prime} \mathrm{s}$ mental capacity (see 'Assessing mental capacity'). Additionally, it would be useful to ask questions related to $\mathrm{P}^{\prime}$ 's personal welfare, and/or property and affairs (see 'Personal welfare and/or property and affairs-related questions').

\section{Evidence to support conclusions about P's mental capacity} Conclusions (e.g. P could not understand simple questions; $P$ made mistakes in simple math; $\mathrm{P}$ did not demonstrate understanding of information relating to more complex decisions such as those requiring a large sum of money or entering into a contract, etc) need to be supported by evidence (e.g. P answered 'I don't know' when asked 'What is your name?'; P could not subtract seven from ten; and P said ' $\$ 10^{\prime}$, when asked how much his flat was worth). If the doctor administers a mental state test on $\mathrm{P}$, he should not just provide a test score (e.g. Abbreviated Mental Test [AMT] score of $1 / 10$ ), but recount what exactly was asked, detail what P's answers were and explain the significance of the test score.

\section{Avoiding unexplained medical jargon}

The medical report is read by laypersons (i.e. lawyers and judges) and not just medical professionals. Technical medical terms in the report should be accompanied by explanations in simple English, or preferably, described in plain English (e.g. 'perseveration' could be replaced with ' $\mathrm{P}$ had the habit of repeating the same word many times when answering a question'; the AMT score could be explained by ' $P$ had an AMT score of $1 / 10$, which suggests severe impairment in P's cognitive ability'; and 'dysphasic' can be explained as 'a speech disorder which impairs P's ability to speak and understand language').

\section{Check before signing off}

As it is difficult to retract a medical report that has been signed and sent off, it is important to read the report carefully before signing it to sieve out any grammatical and spelling errors, and ensure that it: (a) flows smoothly; (b) makes sense and is logical; (c) is clear and concise; (d) is complete; and (e) does not contain any factual errors. If possible, a more experienced, senior colleague should review the report.

\section{ASSESSING MENTAL CAPACITY}

This section sets out the practical questions that a doctor should ask when assessing mental capacity in everyday clinical practice.

\section{What is the 'trigger' for assessing P's mental capacity?}

Some possible scenarios:

- $\quad \mathrm{P}^{\prime}$ s significant other suspects that $\mathrm{P}$ has a mental capacity deficit, but $\mathrm{P}$ needs to make decisions and sign documents. If $\mathrm{P}$ lacks mental capacity, then a deputy application must be made.

- $\quad$ P wants to make an LPA.

- $\quad$ Other matters (e.g. P wants to draft a will.)

In each scenario, it would be useful to find out more about the 'trigger' (e.g. Does P need to give consent for an operation? Is his property slated for an en bloc sale soon?).

\section{How to assess mental capacity}

Section 4(1) of the MCA defines a person who is considered to lack mental capacity in relation to a matter; i.e. if, at the material time, he is unable to make a decision for himself in relation to the matter because of an impairment of, or a disturbance in the functioning of, the mind or brain. A person is considered unable to make a decision for himself if he is unable to understand, retain or weigh information relevant to that decision, or to communicate his decision by any means, according to Section 5(1). Thus, the doctor doing the mental capacity assessment has, as a first step, to ascertain whether $\mathrm{P}$ has an impairment of, or a disturbance in, the functioning of the mind or brain. This is essentially a clinical assessment. As a second step, the doctor has to ascertain whether this condition, if it is present, has rendered $\mathrm{P}$ unable to make a decision in one or more matters, and what these matters are.

\section{Checklist}

Table II provides a checklist of what needs to be done and noted in relation to the mental capacity assessment.

\section{History}

The doctor first needs to take an adequate history from a reliable informant and to supplement this with history from $\mathrm{P}$, where possible. He should also review all past medical records, reports, hospital discharge summaries and other relevant documents when determining whether there is sufficient evidence for the first step of the MCA test (i.e. whether P has an impairment of, or a disturbance in, the functioning of the mind or brain).

\section{Clinical examination}

A clinical examination should follow the history-taking and include an assessment for the presence of cognitive abnormalities, as shown in Box 1.

\section{Bedside cognitive testing}

A 2015 systematic review and meta-analysis by Tsoi et $\mathrm{al}^{(7)}$ described 11 currently available screening tests for cognitive 
Table II. Lack of mental capacity and a checklist on its assessment.

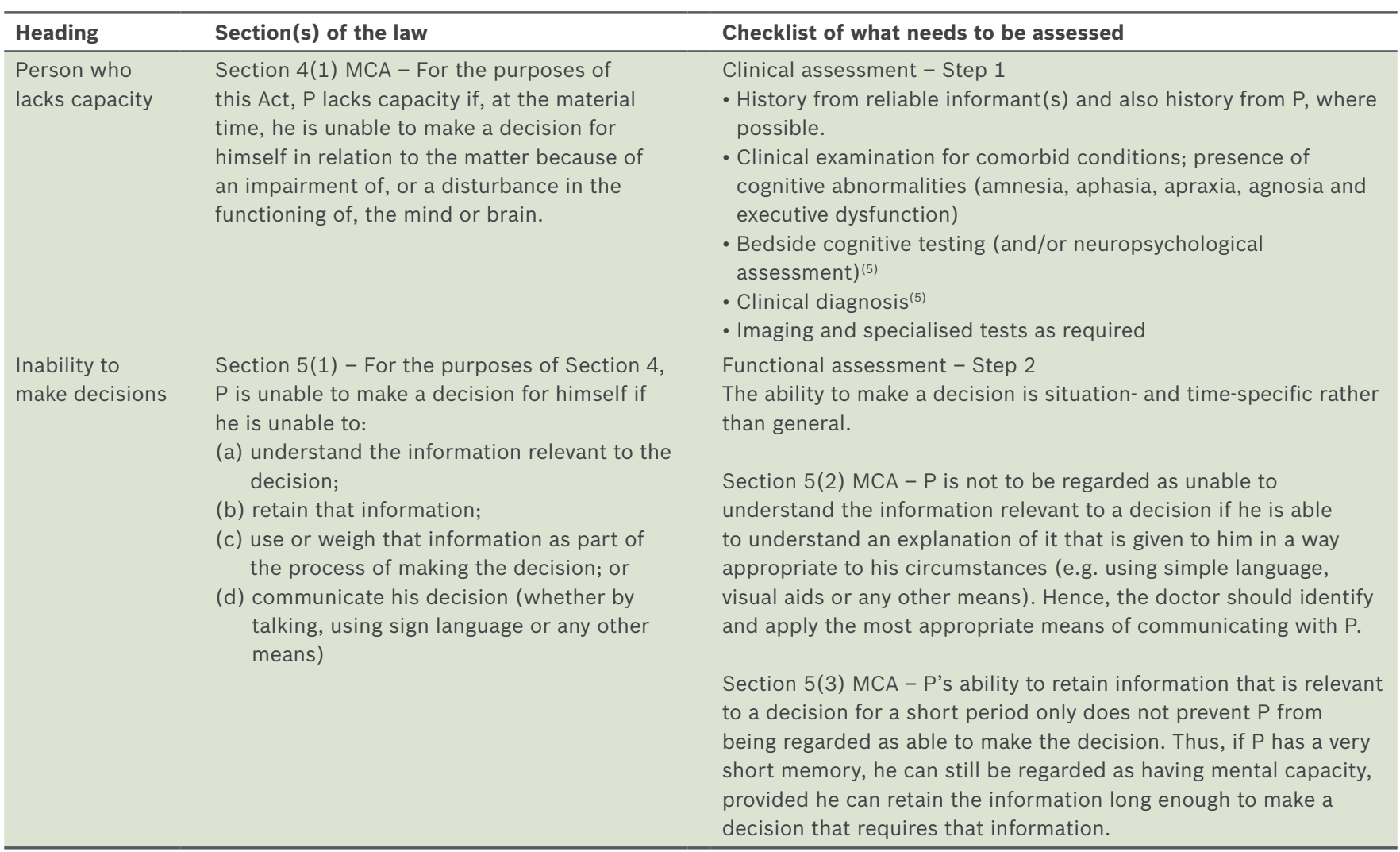

MCA: Mental Capacity Act; P: the person whose mental capacity is being assessed

Box 1. Assessment for the presence of cognitive abnormalities:

1. Note if any of the following are present:

- Amnesia: any forgetfulness?

- Aphasia: any word-finding difficulty or inability to communicate?

- Apraxia: any problems with buttoning or dressing? Any

difficulties with using utensils during mealtimes?

- Agnosia: any problems recognising familiar faces or familiar items?

- Executive dysfunction: any problem handling money (loose change)? Any change in general problem-solving abilities? Is

P's work getting more disorganised?

2. If any of the aforementioned are present, the follow-up question is: do the difficulties interfere with P's independence in self-care, home care and/or living in the community?

function (see 'Staging dementia' for more information on these screening tests). Common screening tests used in Singapore are the AMT, which consists of ten questions, ${ }^{(8)}$ and the Mini-Mental State Examination (MMSE), which consists of 30 questions. Table III shows the AMT used in Singapore.

If $\mathrm{P}$ does not pass the AMT (or other similar tests), a further assessment must be performed to determine whether the cause is a medical problem and, if so, what this medical problem is (e.g. P had a stroke causing vascular dementia, which impairs/disturbs the functioning of his brain). If $P$ fails the AMT or other similar tests for mental capacity and there is insufficient information to determine whether $\mathrm{P}$ has impairment or disturbance of brain or mind, then a referral to a relevant medical specialist (psychiatrist, neurologist or geriatrician) should be made to confirm the medical condition that resulted in the failure of the tests.
Table III. Abbreviated Mental Test Score. ${ }^{(8-10)}$

\begin{tabular}{lcc}
\hline Item & Score & Patient's score \\
\hline What is the year? & 1 \\
What is the time? (within 1 hr) & 1 \\
What is your age? & 1 \\
What is the date of birth? & 1 \\
What is your home address? & 1 \\
Where are we now? & 1 \\
Who is our country's Prime Minister? & 1 \\
What is his/her job? (show picture) & 1 \\
Memory phrase '37 Bukit Timah Road' & 1 \\
Count backwards from 20 to 1 & 1 \\
Recall memory phrase & $\mathbf{1 0}$ \\
Total score &
\end{tabular}

Next, the doctor should ask P questions relating to his personal welfare, and/or property and affairs (depending on the scope of the deputy application or LPA, as the case may be) in order to determine the matters in which P can make decisions. It is useful to shape the questions around the 'trigger' event.

\section{Personal welfare and/or property and affairs-related questions}

Questions that should be asked include: (a) whether P is aware of what medical conditions he has, what treatment he is receiving, what treatment he would like to receive or continue receiving and why; and (b) if $\mathrm{P}$ has property, what he wishes to do with it (e.g. sell it, rent it out or keep it empty; how much to sell it or 
rent it out for) and why. If the person has mental capacity and has not appointed a donee, it may be opportune for the physician to suggest that he consider doing so.

\section{What stage of dementia severity is $\mathbf{P}$ at now?}

The most common impairment or disturbance of the mind or brain on presentation is dementia. Hence, it is preferable for doctors performing the mental capacity assessment and writing reports to be familiar with the various stages of dementia. The severity of dementia determines the extent of $\mathrm{P}^{\prime} \mathrm{s}$ mental capacity impairment. Hence, some staging will be useful as a baseline; over time, further assessments can be performed to follow up on the progress of dementia. Cognitive impairment can range from normal ageing, to mild cognitive impairment $(\mathrm{MCl})$, to dementia (mild to severe).

\section{Comparing normal ageing and mild cognitive impairment}

Normal ageing and $\mathrm{MCl}$ are both accompanied by a decline of cognitive functions with no significant impairment to daily life. In normal ageing, the body and brain slow down, but intelligence remains stable. Hence, more time is taken to process information and memory changes occur, such that it is common to have greater difficulty in remembering names of places, people and things. $\mathrm{MCl}$ differs from normal ageing in that memory problems are severe enough to be noticeable to other people and show up on tests of mental function, but are not severe enough to interfere significantly with daily life.

\section{Progression}

$\mathrm{MCl}$ is a transition period between normal ageing and dementia, and converts to Alzheimer's Disease at an annual rate of 5\%$15 \%$ as compared to normal ageing (1\%). ${ }^{(11)}$ Small decreases in the conversion rate of $\mathrm{MCl}$ to dementia might significantly reduce the prevalence of dementia. Crucially, studies have found that some cognitive brain networks are disrupted in ageing and $\mathrm{MCl}$ populations, and that physical activity can effectively remediate the function of these brain networks. Known predictors of progression of $\mathrm{MCl}$ include: older age, male gender, lower levels of physical activity and a higher Clinical Dementia Rating (CDR) score. ${ }^{(12)}$ In an Italian study of 2,386 individuals with eight years of follow-up, the eight-year incidence of dementia (per 1,000 person-years) was 12.69 in the total sample, 9.86 in subjects with normal cognition at baseline, 22.99 in individuals with cognitive impairment but no dementia, and 21.43 in individuals with $\mathrm{MCl}^{\left({ }^{(13)}\right.}$ Impairment to instrumental activities of daily living was found to be a predictor of progression to dementia. ${ }^{(13)}$

\section{Staging dementia}

Dementia (e.g. Alzheimer's Disease) is characterised by progressive loss of memory and other intellectual abilities serious enough to interfere with daily life. Being able to stage the severity of dementia at the beginning of the illness and follow through with staging at different intervals is important from both the legal and medical points of view. There are three commonly used overall assessment tools: the MMSE, Global Deterioration Scale (GDS) and CDR scale.

The MMSE, also known as the Folstein test, has 30 questions. It is currently the most commonly used tool for cognitive impairment screening due to its simplicity, although the deficiencies of this test threaten its current popularity, namely the limited ability of the MMSE to detect cognitive impairment, its lack of suitability for illiterate subjects and high cost due to its copyright. Newer instruments with greater diagnostic accuracy for detecting cognitive impairment and dementia are now available. ${ }^{(14)}$

Some adjustments to the MMSE English version for use in Singapore are necessary:

(a) Since Singapore has no distinct season changes - spring, summer, autumn or winter - there is a need to modify Question 5 of the standard MMSE ('What is this season?'). It is suggested that a modification of the question to 'What is the upcoming festival?' is probably better than the change suggested by Feng et al, ${ }^{(15)}$ namely 'Without looking at your watch, what time is it?', as it is not uncommon for people without cognitive impairment to be confused about time, especially if they do not lead a very structured day. However, the patient's religious and cultural background should be evaluated before deciding which modification of the question should be used; for example, a Chinese person would probably be more aware of when Chinese New Year is compared to Deepavali.

(b) Consequent to the small geography and territory of Singapore, there is a need to modify the following questions: (a) where are we now?; (b) state? (Question 6); country? (Question 7); town/city? (Question 8); hospital? (Question 9); and floor? (Question 10). Suggested changes to the questions are: (a) where are we now?; (b) country? (Question 6); which part of Singapore - North, South, East or West? (Question 7); which neighbourhood, e.g., Yishun, Toa Payoh, Hougang, Tiong Bahru? (Question 8); hospital? (Question 9); floor? (Question 10).

(c) For ease of word pronunciation, in immediate recall (Questions 11-13) and delayed recall (Questions 19-21), Feng et $\mathrm{al}^{(15)}$ changed the English version objects of 'ball', 'flag' and 'tree', which are single-syllable words, to 'lemon', 'key' and 'balloon' in the Chinese version, which are twosyllable words. This is a reasonable change, which we support.

(d) For sentence repetition, Feng et al ${ }^{(14)}$ changed 'no ifs, ands or buts', in Q24 of the English version, to '44 stone lions', which is a tongue twister when spoken in Mandarin. $\mathrm{Ng}$ et $\mathrm{al}^{(16)}$ used this in their research, as well as 'marah (angry, furious), merah (red), and murah (cheap)' for the Malay version. We also support these changes to the English version of the MMSE when used in Singapore on persons whose primary language is Mandarin or Malay, respectively.

Box 2 shows how MMSE scores can be interpreted for overall staging of dementia in day-to-day functioning. ${ }^{(17)}$ 


\section{Box 2. Interpretation of Mini-Mental State Examination scores:}

- 25-30: Some cognitive impairment, but of questionable significance. May have clinically significant but mild deficits. Likely to affect only the most demanding activities of daily living.

-20-25: Mild cognitive impairment. May require some supervision, support and assistance with some activities of daily living.

-10-20: Clear moderate cognitive impairment. May require 24-hour supervision and assistance with many activities of daily living.

- 0-10: Marked, severe cognitive impairment. Not likely to be testable, and likely to require 24-hour supervision and assistance with all activities of daily living.

The GDS, which is used for overall staging of dementia into one of its seven stages, takes two minutes to complete once the relevant clinical information has been collated. ${ }^{(18)}$ It is used to classify cases by severity in research or service development, but is not often used in Singapore. The CDR scale ${ }^{(19)}$ allows more reliable staging of dementia than the MMSE, and is based on caregiver accounts of problems in daily functional and cognitive tasks. This scale is commonly used in Singapore. A copy of the CDR assessment form by Morris ${ }^{(20)}$ is available online. ${ }^{(21)}$ The CDR scale consists of five stages, namely: (a) Stage 1 - CDR-0 or no impairment; (b) Stage 2 - CDR-0.5 or questionable impairment; (c) Stage 3 - CDR-1 or mild impairment; (d) Stage 4 - CDR-2 or moderate impairment; (e) Stage 5-CDR-3 or severe impairment. Each of these five stages evaluates the patient's functioning in the following six areas: memory, orientation, judgment and problem-solving, community affairs, home and hobbies, and personal care

As $\mathrm{P}$ progresses along the stages, symptoms grow more severe. At Stage 1, P has no issues with memory, is well-adjusted at home and in the world at large, there is no damage to P's ability to function, and he is fully aware of time and place. At Stage 2, $P$ may exhibit slight difficulties, such as failing to handle timing well or to perform at full capacity in the workplace, but he is fully independent. At Stage 3, P may not be able to function independently in some areas of life; following directions and maintaining knowledge of time and place become problematic. At Stage 4, P needs significant help but can function autonomously in some settings. Short-term memory capacity is greatly reduced, and $\mathrm{P}$ is likely to be highly disoriented. At Stage 5, P is completely dependent on others, suffers significant damage to memory and usually shows very little understanding of the world around him.

\section{CONCLUSION}

Medical practitioners need to familiarise themselves with the template for medical reports (Form 224) for deputy applications, the legal requirements for such reports, and build skills and confidence in the assessment of mental capacity in accordance with the MCA framework.

\section{ACKNOWLEDGEMENTS}

The authors are grateful to Dr Colin Tan, District Judge, for his comments on the early draft of the portion of this article pertaining to medical report writing and to Ms Tan Rou'en, Assistant Director, Legal Aid Bureau, Singapore, for her help with the article. However, any errors and views expressed are entirely the authors' own. In particular, they do not represent the views of the Legal Aid Bureau, Ministry of Law or Family Justice Courts, Singapore.

\section{DISCLAIMER}

Please note that this article is not intended to give or be a substitute for any legal advice. The help of a lawyer should be sought if a doctor has a query on any specific legal issue in a Mental Capacity Act matter.

\section{REFERENCES}

1. Singapore. Mental Capacity Act 2008, c 177A, s 11 .

2. MCA Online Training Module: Assessment of Mental Capacity under the Mental Capacity Act [online]. Available at: https://smacme.talentlms.com/catalog/info/ id:115. Accessed December 13, 2016.

3. Singapore. Mental Capacity Act 2008, c 177A, s 20

4. Thirumoorthy T. Written Medical Communication - Skills in Writing Medical Reports. In: SMA News [online]. 2016; 46:16-8. Available at: https://www. sma.org.sg/UploadedImg/files/Publications\%20-\%20SMA\%20News/4602/ Professionalism.pdf. Accessed December 13, 2016.

5. Singapore. Family Justice Courts Practice Directions, para 54(9)(e).

6. Legal Aid Bureau, Singapore. Medical Report for Mental Capacity Act applications [online]. Available at: https://www.mlaw.gov.sg/content/lab/en/ news-publications/medical-report-for-mental-capacity-act-applications.html. Accessed October 6, 2016.

7. Tsoi KK, Chan JY, Hirai HW, Wong SY, Kwok TC. Cognitive tests to detect dementia: a systematic review and meta-analysis. JAMA Intern Med 2015; 175:1450-8.

8. Ministry of Health, Singapore. MOH Clinical Practice Guidelines 3/2007: Dementia [online]. Available at: https://www.moh.gov.sg/content/dam/ moh_web/HPP/Doctors/cpg_medical/current/2007/CPG_Dementia_Booklet. pdf. Accessed October 6, 2016.

9. Sahadevan S, Lim PP, Tan NJ, Chan SP. Diagnostic performance of two mental status tests in the older Chinese: influence of education and age on cut-off values. Int J Geriatr Psychiatry 2000; 15:234-41.

10. Kandiah N. Overview of dementia and diagnosis of dementia. Sing Fam Phy 2013; 39:8-14.

11. Huang P, Fang R, Li BY, Chen SD. Exercise-related changes of networks in aging and mild cognitive impairment brain. Front Aging Neurosci 2016; 8:47.

12. van Rossum ME, Koek HL. Predictors of functional disability in mild cognitive impairment and dementia. Maturitas 2016; 90:31-6.

13. Di Carlo A, Baldereschi M, Lamassa M, et al; Italian Longitudinal Study on Aging Working Group. Daily function as predictor of dementia in cognitive impairment, no dementia (CIND) and mild cognitive impairment (MCI): an 8-year follow-up in the ILSA study. J Alzheimers Dis 2016; 53:505-15.

14. Carnero-Pardo C. Should the Mini-Mental State Examination be retired?. Neurologia 2014; 29:473-81.

15. Feng L, Chong MS, Lim WS, Ng TP. The Modified Mini-Mental State Examination test; normative data for Singapore Chinese older adults and its performance in detecting early cognitive impairment. Singapore Med I 2012; 53:458-62.

16. Ng TP, Niti M, Chiam PC, Kua EH. Ethnic and educational differences in cognitive test performance on mini-mental state examination in Asians. Am J Geriatr Psychiatry 2007; 15:130-9.

17. Dementia Today. Mini-Mental State Examination test [online]. Available at: http://www.dementiatoday.com/wp-content/uploads/2012/06/ MiniMentalStateExamination.pdf. Accessed October 6, 2016

18. Sheehan B. Assessment scales in dementia. Ther Adv Neurol Disord 2012; 5:349-58.

19. Lim WS, Chong MS, Sahadevan S. Utility of the clinical dementia rating in Asian populations. Clin Med Res 2007; 5:61-70.

20. Morris JC. The Clinical Dementia Rating (CDR): current vision and scoring rules. Neurology $1993 ; 43: 2412-4$.

21. Dementia Collaborative Research Centres. Clinical Dementia Rating Form [online]. Available at: http://knightadrc.wustl.edu/cdr/PDFs/CDR_Table.pdf. Accessed October 6, 2016.

\section{RECOMMENDED READING}

1. Singapore. Code of Practice: Mental Capacity Act (Chapter 177A) [online]. Available at: https://www.publicguardian.gov.sg/opg/Documents/CSC.MSF. OPGWebsite/Documents/CodeOfPractice.pdf. Accessed December 13, 2016.

2. Singapore. Mental Capacity Regulations 2010, c 177A, s 105/2010. In: Singapore Statues Online. Available at: http://statutes.agc.gov.sg/aol/search/ display/view.w3p;page $=0$; query $=$ Compld\%3A02935a0d-a367-4c1e-92ac4c75a38408ae;rec=0. Accessed December 13, 2016. 